\title{
DESCRIPTIONS OF INTERPRETING AND THEIR ETHICAL CONSEQUENCES
}

\author{
Uldis Ozolins \\ University of Western \\ Sidney, Australia \\ u.ozolins@uws.edu.au
}

\begin{abstract}
The current array of descriptions that are given of interpreting outside the conference room has bedeviled the field: from 'community interpreting' to 'dialogue interpreting' to 'public service interpreting' to 'ad hoc interpreting' to 'non-professional interpreting'. Some descriptions avoid 'interpreting' altogether - 'linguistic mediation', 'cultural mediation' etc. Significantly, self-ascription by the practitioners themselves often does not match these imposed descriptions.
\end{abstract}

Yet each description carries with it, implicitly or explicitly, a specific view of ethics, tied closely to perceived roles of interpreters, but often encompassing assumptions about tasks, personal or professional characteristics, or status.

This messy terminological terrain is surveyed to reveal some altogether clear distinctions that can help our understanding of differentiating and common elements in interpreting. Building on that, the ethical implications of different descriptions are categorised to show that ethical responsibility in interpreting situations rests not with the interpreters alone, but with other players, particularly institutional players, in contracting language services.

\section{Introduction}

The current array of descriptions that are given of interpreting outside the conference room has bedeviled the field. Numerous authors have pointed to these variations, one of the first being Gentile as early as 1997 in the first Critical Link collection, in his pointedly titled paper 'Community interpreting or not'. He lists "cultural interpreting, ad hoc interpreting, liaison interpreting, three-cornered interpreting and there has been a further suggestion of 'interprète social" (Gentile 1997: 110). Gentile uses this array to demonstrate how difficult it is to come to a definitive description of community interpreting or any of its offered adjectival forms; nor do the descriptions often do anything to distinguish their supposed type of interpreting from any other type; he argues that "what we are talking about is simply interpreting".

Yet the descriptions continued to multiply from all the places around the world inventing liaison interpreting at this time (Erasmus 1999). Pöchhacker (2008) later extends the discussion of the many descriptions of interpreting to take in terminology that avoids the term interpreting at all in favour of stressing mediation: cultural or linguistic, a phenomenon particularly found in Italy and Spain and discussed further below.

In one sense, such attempted descriptions radically miss the mark, in that almost all interpreters throughout the world, whatever their setting for interpreting, refer to themselves as - 'interpreters'. Unmarked. The various adjectives may be used on occasions for specific reasons (e.g. 'court interpreters' in the USA), but most interpreters around the world do not usually use such self-descriptions as 'community interpreters' or 'liaison interpreters' or 'public service interpreters' and certainly not 'ad hoc interpreters'. For many of these authors, practitioners and authorities inventing these descriptions, the unmarked variety of interpreting may remain conference interpreting, but for others conference interpreting is not even on the horizon. Exceptions to the universal use of 'interpreter' are those cases where there is no 
reference to interpreters at all but to e.g. cultural mediators or linguistic mediators, and here self-description by practitioners may match such descriptions, for authorities paying for these services have ensured such descriptions have policy or even legislative force (Valero-Garcés 2003, Pöchhacker 2008, Baraldi 2012).

Yet in another sense, such descriptions of interpreting are of great interest, both for understanding the contexts in which various interpreters work, and for understanding how such practices are seen by others. Every categorisation implies a hierarchy or a spectrum of practice, and each description of what may be termed adjectival interpreting also contains ethical implications, for many of the descriptions ascribe agency or lack of agency, or status or lack of status to interpreters in varying degrees, and corresponding responsibility or otherwise to those working with interpreters.

This paper argues that despite the apparent confusion, it is possible to get conceptual clarity on these distinctions. It also argues that the ethical implications - explicit or implicit of these various descriptions of interpreting are important to understand in the development of what is now a wide spectrum of interpreting practice. Understanding the adjectives may be the first step to transcending them.

\section{Descriptions of interpreting by mode}

First, there are ways of providing simple distinctions between conference interpreting and all other kinds of interpreting according to mode: most cryptically this is provided in Wadensjö's distinction between dialogic and monologic interpreting settings (1998). Such a linguisticoriented description has the advantage of comprehensiveness and exhaustiveness and immediately stresses personal interaction as a keystone of one form of interpreting as opposed to rendering of a (usually) uninterrupted text in the other. Note, however, that this distinction is about modes of interpreting, not about fixed practice of interpreters of various kinds: a conference interpreter may well engage in dialogic interpreting in small meetings or face-toface encounters between delegates or other interlocutors, and interpreters who overwhelmingly work dialogically may be called on to interpret speeches to groups on occasions, or perform simultaneous interpreting as chuchotage.

However, such a monologic/dialogic distinction or other proxies such as unilateral/bilateral interpreting (de Pedro Ricoy 2010), are not distinctions used by any practitioner, and leaves us in a linguistic stratosphere. More informally but also more informatively, the distinction can be made between conference interpreting and liaison interpreting, or more simply still, between simultaneous interpreting and dialogue interpreting, though this is too simplistic - given the different modes the same interpreters may use on different occasions - as mentioned above.

For simple consistency, this paper henceforth uses the distinction between liaison interpreting (Gentile et al 1996) and conference interpreting, but with a proviso that these are distinctions of mode alone: issues of status, professionalisation, sites and other aspects of interpreting work must be treated separately and cannot be deduced from the mode of interpreting alone. As an example, some descriptions of mode are internal to the dialogic/liaison side, for example Niska's (1991) contact interpreting, defined in relation to interpreting for immigrant populations and mainstream institutions, or Erasmus' (1999b) escort interpreting, defined in relation to work with executives, business people and diplomats - thus, mode alone does not say anything about the status of participants. There have been many other fine-grained taxonomies of the various modes of interpreting over the years, usefully surveyed by Pöchhacker (2008). 
Significantly for our discussion, at this level of mode there are no ethical implications that obviously present themselves as being different for one mode or the other, no clear way in which ethical demands in one context would differ from that of another in such ethical considerations as accuracy or impartiality or relations to other participants. We do understand that as a matter of practice most liaison situations will be face to face encounters for the interpreter whereas most conference interpreting situations will have the interpreter at some remove from, and often only technologically linked to, other participants, but this does not prima facie cause us to assume different ethical principles of practice. However, as we delve further into the various descriptions of liaison interpreting, we will see the ethical implications that arise, when the interaction that is the hallmark of liaison interpreting is looked at more closely in specific sites and contexts. For Wadensjö argues that the dialogic mode of interpreting will ipso facto involve not only translation but importantly coordination of discourse, in a way that monologic interpreting characteristically will not. While this of itself need not have any ethical implications (for theoretically and practically any interlocutor may engage in coordination of discourse in an interpreting situation, not the interpreter alone), the exigencies of many interpreting situations place particular ethical burdens upon interpreters for a variety of very specific reasons, discussed immediately below.

Here we can summarise these descriptions of mode in this table:

Table 1: Interpreting as mode

\begin{tabular}{|l|l|l|}
\hline Mode & $\begin{array}{l}\text { Monologic } \\
\text { (Conference) } \\
\text { (Simultaneous) }\end{array}$ & $\begin{array}{l}\text { Dialogic } \\
\text { (Liaison) } \\
\text { (Dialogue, bilateral... etc) } \\
\text { (Contact, escort...) }\end{array}$ \\
\hline
\end{tabular}

\section{Descriptions of interpreting by settings}

Several of the descriptions of liaison interpreting specifically make distinctions according to settings in which such encounters take place. These settings can be described on the one hand in generic terms or on the other hand in institutional-specific terms.

\subsection{Generic descriptions}

Such descriptions encompass community interpreting, public service interpreting or its French proxy Interprétariat, or the largely Canadian cultural interpreting, or (most vaguely) social interpreting, where Gentile's early hint of this foreshadowed the actual use of this term in Belgium in particular (Vermeiren et al 2009). In some cases these generic descriptions are formalised in actual qualifications, training programs or positions eg the National Register of Public Service Interpreters in the UK; the French Interprétariat implies a whole apparatus of a service to provide interpreting between non-French speaking residents or visitors and French institutions, much along the lines of Public Service Interpreting, but in a country where interpreting per se is strictly seen as conference interpreting.

There are now also a small number of ways in which community interpreting is becoming institutionally entrenched, in particular in some interpreting courses which may be specifically designated as community interpreting courses (eg Leicester University UK, Bar 
Ilan University Israel), or in such initiatives as the international community interpreting database at York University in Canada

(www.yorku.ca/comindat/comindat.htm).

For the most part, however, community interpreting remains a catch-all term with many different perceptions of what it means, and at times strong professional and even institutional views of its appropriateness. In the UK for example, Corsellis (2008:6-7) argues that the term 'community interpreting' was not favoured as it created too much confusion with the terms European community, as well as concerns that community interpreting was associated with poor quality, untrained interpreters who also assumed other roles; this became an institutional decision in 1990, when the Institute of Linguists adopted public service interpreting as its nomenclature, implying that practitioners were "impartial and qualified" (Erasmus 1999b: 50). This was the outcome of a period of debate in Britain where issues of advocacy and an activist role for interpreters had been strongly proposed, beginning with Shackman's seminal The Right to be Understood (1984). Erasmus quotes the London Interpreting Project as promoting such an activist vision of the community interpreter:

For the sake of brevity, and because we believe that the term community interpreter automatically implies an element of advocacy and a commitment to the interpreter's community, we have frequently used this term to encompass advocates and linkworkers. (Sanders n.d, quoted in Erasmus 1999b:50).

This quotation is striking not so much for its view of advocacy, an issue for many settings of interpreting as we shall see, but for the identification of "a commitment to the interpreter's community" as being a crucial component of a community interpreter's role. This highlights an important feature of the identity of interpreters as being closely tied to the community of their origins, and are identified as such not only by themselves but those who work with them and define them. Given that certainly in immigrant situations, virtually all interpreters of minority languages will be of that immigrant background themselves, rather than members of the host community who have in whatever way learnt that other language, then ethical issues arise very quickly from that identification: on the one hand, if those who work with such interpreters, or write about them, believe that these interpreters have a "commitment to the interpreter's community", this identification with the respective ethnic community may see them as not being impartial facilitators of communication; on the other hand, such a commitment may be seen as having the capacity to advise on community issues or to engage in cultural brokerage, thus facilitating integration and having positive outcomes beyond only interpreting between languages.

Yet the view of community interpreting as encompassing poor quality interpreting or being linked to advocacy or a necessary ethnic link is strongly contested by others. Corsellis (2008) claims that the term community interpreting is accepted and has a "long and distinguished tradition" and high standards in countries like Australia, an observation that leads to some perhaps unintended paradoxes: as Gentiles (1997) argues, the term community interpreting is not used in Australia, but only interpreting, yet Australia's most prominent author in this field Sandra Hale (2007) has written the leading text entitled - Community Interpreting! For Hale, this term generically refers to a whole gamut of largely public sector interpreting - health, social services, legal, administrative etc, and she sees this as a fully professional field, or capable of being such anywhere in the world, with certification standards, codes of ethics and training. She is certainly aware of shortcomings of provision and still underdeveloped areas of professionalisation, but critically Hale sees this interpreting as implying impartiality as the centerpiece of its role, and disputes the need for advocacy, interpreter intervention or any ethnic commitment on the part of community interpreters: their 
commitment is to the profession and the need to interpret accurately, completely and impartially.

The largely Canadian description cultural interpreting (Mesa 2000) presents another significant generic description. This was clearly a marked description in relation to the unmarked (ie conference) interpreting; it covered interpreters who under any other description would have been simply that, interpreters, but in a context where it was the cultural difference of the non-speaker of the dominant language, the immigrant or indigenous, that was assumed to create communication difficulties, not simply the linguistic difference. Its use has diminished even in Canada; as one example, the National Standard Guide for Community Interpreting Services there expounds an ethics of impartiality, explicitly distances itself from sector-specific definitions such as are often found in health interpreting (see below) and offers a critique of cultural interpreting. It argues that cultural interpreters had a role to bridge “"cultural misunderstandings' between service providers and non/limited English speakers", but that such intervention created conflict for all parties, went against the principle of impartiality, "and furthermore begs the question of the demonstrated competence of the interpreter to perform that function" (NSGCIS, 2007:21).

Other generic descriptions such as 'social interpreting' (Vermeiren et al 2009) largely reflect the scope (and contestation) analysed for community and cultural interpreting.

Other descriptions of interpreting in terms of setting are more specific, and the fields of health/medical interpreting and judicial/legal/court interpreting in particular have in some constituencies led to separate structures, policies and professional identities. This is most apparent in the USA where the fields of judicial interpreting and health interpreting have had quite distinct logics of development, with court interpreting being significantly recognised in policy with federal legislation such as the federal Court Interpreters Act in 1978. Court interpreting is also favoured in such countries as Sweden (Nörstrom et al 2011) and Austria (Pöchhacker 1997) in terms of certification and remuneration, where a tripartite distinction of conference/court/community (or other description) interpreting holds sway.

It should be noted that each of these generic descriptions of interpreting raises problems of definition before we can even consider ethics, as we have seen with community interpreting above. For example, the description of Public Service Interpreting begs the question of what is the public service, for this concept may cover widely different practices in various countries - public utilities? privatised public utilities? insurance? NGOs? public or private health systems or health maintenance organisations? Interpreters may work across such areas seamlessly whether they are strictly 'public service' or not; as one example, arguably over half the interpreting situations described in Kelly's Telephone Interpreting (2008) may not fit into the UK frame of public service work.

Looking to the basis of ethics then arising from this description, Public Service Interpreting implies that interpreters are within the institutional and ethical setting of public service work, in which interpreters are recognised and employed to ensure principles of equity, access, due process and response to need for those not speaking the dominant language(s) of the country. This has also been the underpinning principle of development of language services in countries that do not specify the Public Service appellation (Australia, Sweden) and which generically refer to their field as interpreting but may be categorised by others as community interpreting. Significantly however, principles of access or equity or due process are first and foremost public policy and institutional imperatives and ethical principles, and are not in themselves principles that prima facie relate to interpreting or have evolved from the interpreting profession; this raises the question of the relation between government or institutional policy and professional initiative in establishing the liaison interpreting field in each case. 
In some cases institutional imperatives and professional initiative have been closely linked in developing structures and ethics: in the UK case this arose from the strong involvement of a professional organisation - the Institute of Linguists - that had already established itself as a body for conference interpreters and undertook the complex task of building an infrastructure for non-conference interpreting and convincing government policy makers to create the National Register for Pubic Service Interpreters [NRPSI] (Corsellis 2008).

While the UK example shows a fortuitous coalition of a strong professional body and public policy bodies, in other cases the genesis for language services has been more institution-driven, as in Australia and Sweden where strong immigration-focused government policies developed language services and accreditation systems with a relatively weak profession evolving in their wake (Ozolins 2000, 2010). Another very much top-down instance of state initiative is with the French Interprétariat (Sauvêtre 2000), which emerges perhaps unexpectedly as the first significant large-scale language service, having been established in 1970, providing interpreting for contact between immigrants and French institutions, as well as providing an ecrivain public service of preparing written submissions in appropriate register to forward to French institutions The concern that this evoked for another category of interpreters was shown in the damning of such an institution by the doyen of conference interpreting, Danica Seleskovitch, as a'barabarism' in its employ of untrained interpreters and lack of standards and, most critically, lack of control by the profession over its conditions (Seleskovitch 1985, Pöchhacker 2008).

\subsection{Institution-specific descriptions}

The descriptions of specific settings will carry with them a set of ethical principles of an importantly different kind to generic descriptions, as there is a strong institutionally-specific basis to interpreting and attendant ethics, with consequently often quite varied perceptions of ethics. Taking the USA example, the code of ethics for the National Association for Judicial Interpreters and Translators [NAJIT] gives us perhaps the most specific stipulation of interpreter behavior of any code. It firmly sets itself against any intervention or advocacy, stipulating that the interpreter "shall not give advice to the parties or otherwise engage in activities that can be construed as the practice of law" (Canon 4) (www.najit.org/about/NAJITCodeofEthicsFINAL.pdf)

NAJIT's first canon of its code, on Accuracy, spells out the court interpreter's role in great detail:

Canon 1. Source-language speech should be faithfully rendered into the target language by conserving all the elements of the original message while accommodating the syntactic and semantic patterns of the target language. The rendition should sound natural in the target language, and there should be no distortion of the original message through addition or omission, explanation or paraphrasing. All hedges, false starts and repetitions should be conveyed; [...] The register, style and tone of the source language should be conserved.

Guessing should be avoided. Court interpreters who do not hear or understand what a speaker has said should seek clarification [...] (ibid)

While legal interpreting codes are largely concerned with controlling the behavior of the interpreter, on certain points such a getting clarification, or asking for repetition or ensuring turn-taking, the codes do mandate the interpreter controlling the behavior of others. Yet this does not end the matter of court interpreting, as there has been controversy over the ethical stance of court interpreters when they see palpable injustices take place, and Camayd- 
Freixas (2013) argues that basic principles of justice and procedural fairness must be built into codes of legal interpreting, as some codes in the USA are attempting to do; this may well have implications as well for other areas or liaison interpreting, as discussed earlier in relation to access and equity principles.

Meanwhile, the codes in the much larger health interpreting field in the USA all agree on a role for interpreters that would not be considered appropriate for, say, legal or immigration interpreting: the four roles cited the National Council for Interpreting in Health Care [NCIHC] and California Healthcare Interpreter Association [CHIA], among others, cite the health interpreter role as embracing

Message converter

Message clarifier

Cultural clarifier

Patient advocate.

(CHIA, 2002, NCIHC, 2004)

Ethical implications of such roles are quick to arise and in some ways may be subject to the same critique of cultural interpreting already mentioned. The genesis of such role descriptions are not difficult to find: the concern has been that those not speaking the majority language are hugely disadvantaged in institutions, in this case health institutions which in many explicit or implicit ways discriminate against minorities, or attend to their needs inadequately, even unwittingly. In the face of this interpreters are often the only health workers able to raise issues and advocate for patients. Cultural clarification is one less confrontational aspect of this, where minorities need to understand institutional practices and institutions need to understand the cultural needs and differences of minorities that may affect health care.

Without engaging in a full-scale ethical evaluation of such roles, two elementary question may be worth asking to clarify their ethical implications. The first is simply, do interpreters undertake such roles? There is it seems inadequate literature to demonstrate the extent to which interpreters do in fact engage in patient advocacy, while there is a good deal of literature to show that health interpreters often play the role of institutional advocate, getting the patients to answer questions in the forms put to them by clinicians, or conform to institutional demands (Angelelli 2004a). Likewise, the extent to which cultural clarification obtains in the health interpreting field is also difficult to determine: Pen and Watermeyer's (2012) sensitive study of interpreting in aphasia cases leads to a wider theoretical question of whether cultural clarification or other forms of cultural brokerage are most readily seen when normal forms of communication and straightforward attempts at interpreting break down?

The immigration/asylum seeker area is identified here as a specific site as although there is rarely a specific infrastructure or career identity for interpreters in this area as there may be in health or legal interpreting, some significant ethical issues have arisen here. For some countries of previously little immigration (eg Finland, Norway), the recognition for the need for organised language services largely arose with the issue of asylum seekers; in the growing body of research there is considerable analysis of the demands of asylum seeker interpreting (eg Pöllabauer 2004, Inghilleri 2011). A very forceful ethical intervention here is that of Barsky (1996), who argues that interpreters are in a very powerful position to influence the outcome of asylum hearing, and should not confine themselves to an impartial role but recognise the unequal power relationship between asylum seekers and immigration officials. As asylum seekers rarely understand the bureaucratic exigencies of the questions they are answering or rarely have the resources to present themselves in a strong, competent and favourable light, it is the interpreter who must provide, in Barsky's view, renditions of the asylum seekers' stories in powerful and convincing terms, to equalise the power 
relationship. Barksy has so far found little support for his views among professional interpreting bodies, and very mixed responses from other authors, with Fenton (2004) pointing to the dangers of such an approach - dangers to all parties - but Inghilleri (2011) expressing some support. Yet while Barsky's view may be considered extreme, it does bring into focus the extent to which sector-specific approaches to interpreting take on ethical challenges that are embedded in their specific context. While many may not follow Barksy's high-powered interventionism, one issue that clearly arises in this setting is "interpreting for the record", where Pöchhacker \& Kolb (2009) show in almost alarming fashion both that what appears on asylum seeker hearings written records is often at some remove from the interpreter's (and applicant's) rendition; and that interpreters are cognisant of that and shape their own renditions to be better reflected in the official record. This concern may also be wider, for example relating to police interviews or any other forensic interviews which are not recorded in audio or video.

To the extent that such specific areas of practice are categorised as different to each other, to that extent we find a degree of 'ethical capture' of that field of interpreting by its institutional setting, so that for example health interpreting descriptions of role place the duty of care to patients highest in ethical priority, and most court interpreting codes (despite the arguments of Camayd-Freixas) place accuracy and impartiality as their centerpiece.

Finally among the specific fields, the area of business interpreting is perhaps the least covered or researched, and certainly less thought about in terms of ethics. The small literature in this field (Ko 1996, Takimoto 2006, Dodds 2011) nevertheless makes some important contributions to unlocking this field to scrutiny and identifying its particular ethical ethos. Business interpreting as a field is more amorphous perhaps than any other specific sector mentioned here, sometimes being serviced by conference interpreters, sometimes by interpreters without a conference background, sometimes by in-house bilinguals. Crucially, business interpreting differs from other sectors mentioned here as the interpreter is in a purely market situation, different from say in pubic service interpreting where an interpreter is provided as a result of an entitlement: a guarantee or obligation (however strongly or weakly pursued in policy) that those who do not speak the majority language or institutions that need to communicate with such clientele employ interpreters to facilitate that communication. Business interpreting relates only to the needs of the parties to communicate in order to secure deals, and while the importance of accurate interpreting are as strong here as anywhere, issues such as impartiality or role are often subservient to the needs of the negotiating party. Takimoto (2006) relates how interpreters that work across different sectors feel that often in business interpreting they may go against codes of ethics they obey elsewhere: in business settings there is a focus on communicative efficiency so that interpreters will summarise or expand explanations, or in certain circumstances may censor messages to avoid conflicts arising which could derail negotiations. They may also be expected to perform a host of other roles besides interpreting because of their clients' lack of understanding of the interpreting role and the close and personal ties established during long assignments. - all this makes performance in business interpreting fraught in terms of ethics. The present lack of research and publication, always partly obscured by commercial in confidence considerations and reluctance of interpreters to go on the record, means that business interpreting remains perhaps the least understood sector of interpreting; however, taking a broader view it should be possible to connect these situation with those interpreting situations in other sectors where the exigencies force interpreters into other roles, or force them to have to deal with interlocutors with little understanding of interpreting and a variety of expectations of what interpreters should do. Significantly, of all sectors, business interpreting is singular in not having spawned codes of interpreting ethics. 


\subsection{Generalist and specialist ethics}

In comparison to these specific sectors, the more generically described areas of interpreting assert a more universalistic ethics, and doubt that ethics should be modified for specific fields of interpreting. For example, the more generic Code of ethics, eg in Australia, specifically eschew advocacy and downplay cultural clarification, but also downplay sector-specific ethics, assuming that a generic code of ethics based on impartiality, confidentiality, competence and understanding of role boundaries is suitable for all contexts of professional interpreting (AUSIT 2012). The Canadian National Standards already mentioned specifically argues that a universal ethics for interpreters applies to all sectors, and is supported in this by the Canadian Health Interpreting Network among others (NSGCIS, 2007). SchwedaNicholson as early as 1994 identified the common features of both sector-specific and generic codes, particularly their deontological nature and espousing of a set of principles of the interpreter's overall role; competence and required skill; impartiality; completeness and accuracy, conflict of interest; confidentiality; and continuing professional development, a list largely confirmed by Hale's survey of codes of ethics nearly a quarter of a century later (2007).

Yet evolving a convincing generic ethics for this field has been difficult even for such a well-credentialed and well-supported body as the National Register for Pubic Service Interpreters [NRPSI]. Its own code of ethics is very equivocal about the role of its interpreters, and makes an unusual distinction in its code that brings back sector-specific requirements in a questionable way. The code argues for apparently two different roles of interpreters:

5.7 Practitioners carrying out work as Public Service Interpreters, or in other contexts where the requirement for neutrality between parties is absolute, shall not enter into discussion, give advice or express opinions or reactions to any of the parties that exceed their duties as interpreters; Practitioners working in other contexts may provide additional information or explanation when requested, and with the agreement of all parties, provided that such additional information or explanation does not contravene the principles expressed in 5.4. (www.nrpsi.co.uk/pdf/CodeofConduct07.pdf)

Clause 5.4 states that "Practitioners shall interpret truly and faithfully what is uttered, without adding, omitting or changing anything; in exceptional circumstances a summary may be given if requested." Yet in a puzzling omission, the code does not identify which contexts require "absolute" neutrality and which do not. And it remains obscure how the permission to "provide additional information" can be reconciled with the requirement of 5.4 to interpret "without adding, omitting or changing anything".

Even here in a generic code, the sector-specific requirements exercise a shadowy pull in particular directions, without explicitly identifying themselves and leaving interpreters and those who rely upon them in a potentially uncertain position. In literature on ethics in interpreting, no theme is more commonly heard than that of interpreters identifying a disjunction, a gap between principles espoused in codes of ethics and the realities of interpreters' daily work and expectations they are subject to (Mikkelson 2000). While this tangled and complex subject is beyond the reach of this article, it should be noted that such gaps have been argued to exist both for sector-specific codes (eg Angelelli 2004a) and for generic codes (Ko 2006); where generic codes are themselves confused or ambivalent, however, the opportunity for accusations of a gap are even stronger. However, the argument that gaps inevitably exist between codes and practice is contested by Hale (2007), Tebble (2012) and Dean and Pollard (2011), the latter arguing that 
...codes do not interpret themselves, they require intelligent deployment. On the other hand, if they are mistakenly presented as a set of rules, they are bound to be inadequate to the range of particular situations faced by practitioners (Dean \& Pollard 2011: 187)

These distinctions of settings and generic/sector-specific descriptions of interpreting are of interpreting are summarised in the following table:

Table 2: Interpreting as setting

\begin{tabular}{|l|l|l|l|}
\hline Settings & Conference & Generic & Specific \\
\cline { 3 - 4 } & Social & Court/Legal/Judicial \\
& Community & Health \\
& & Public service & Social security \\
& Interprétariat & Immigration/asylum \\
& Cultural & seeker \\
& & Business \\
\hline
\end{tabular}

\section{Descriptions of interpreting according to professional status}

The third way in which descriptions of interpreting can be categorised is by the concern for professional status or lack thereof, and here we come across a series of descriptions that either explicitly state the basis of recruitment ('voluntary interpreter' in any situation; or 'locally hired interpreter' or 'civilian interpreter' in usually conflict situations), or explicitly pronounce the non-professionalism of the practitioner (ad hoc interpreter; non-professional interpreter) or, in a slightly different context, natural interpreter.

Many of these descriptions are almost always applied to practitioners by others, not by themselves, particularly for the latter category. Such descriptions arise often in situations where professional interpreter services are unknown or poorly established, and often professionals or officials will use any apparent bilingual as an interpreter.

The central issue of ethics here can be succinctly stated: to the extent that professionals or officials recruit and employ persons who do not see themselves or are not seen by their employers as professionals, the only issue of ethics is for those professionals or officials employing such persons. And the question is whether using persons of such status accords with those professionals' or officials' own standards of practice and ethical codes.

But descriptions - or more accurately, accusations - of non-professionalism can also come as put-downs by those who know little about liaison interpreting, as in Seleskovitch's attack on the Interprétariat above. But it should be said immediately that such views are not confined to conference interpreters alone - this author has heard people involved in professional interpreting as liaison interpreting scoff at the appearance of conferences now devoted to 'non-professional interpreting'.

For those in the interpreting profession, the use of non-professional interpreters is highly worrying, as in Pöchhacker's description of a daughter being used to completely inadequately interpret for a health situation (2012). Yet often such situations are written about not for reasons of interest in professional interpreting but to analyse aspects of cultural differences or intercultural communication or linguistic representation (Meyer 2002, 2012). In situations of undeveloped language services, or where institutional attitudes prevail that non-speakers of the majority language must provide their own solutions to communication, such interpreting activities taken on by non-professionals may be all that is possible, and only a long march through the social and linguistic institutions policy settings will bring change. 
Yet Boéri (2012) has usefully problematised the notion of ad hoc interpreter by looking at how the interpreting at the Nuremberg trials (a touchstone of interpreting development for the conference interpreting profession) was in fact an ad hoc situation with no-one having interpreted before in such circumstances with such technology, and qualifications of interpreters varying radically. Ad hoc situations clearly vary according to the resources put into them to make them work.

Conflict situations present a particular case where the descriptions come with a clear boundary-maintenance function as locally recruited interpreters in places such as the Balkans, Iraq or Afghanistan are sometimes recruited by and work with professional military or international institution conference interpreters. Authors themselves disagree with each other on whether such interpreters should be regarded as professionals - Thomas (2003) writing on locally recruited interpreters in Bosnia sees them as professionals who often work under threats - sometimes from both sides - and need international protection for their work, which is too often denied. Inghilleri 2011) on the other hand, writing on Iraq, while agreeing on the "contingent nature" of such interpreters and their lack of protection, nevertheless wants to use these interpreters as an example of the impossibility of interpreters to be neutral. This is a debate that has had some saliency in other contexts (Metzger 1999, Angelelli 2004b) but which is used in a particular way here, for Inghilleri wishes to ask "whether or how [...] interpreters, like their soldier counterparts, might assume some responsibility for the ways that wars are conducted" (Inghilleri 2011: 99). She goes on somewhat curiously to ascribe to them full moral responsibility as they become not only "linguistic conduits" but "conduits for the military", which render them "by definition" non-professionals and thus their decision to work in this case for the American military is "often grounded more in ordinary morality given the absence of a role morality attached to any professional status as an interpreter" (ibid: 100). Given her explicit opposition to the war, Inghilleri's stance on the one hand gives us a somewhat bizarre argument for the non-neutrality of interpreters, but on the other she seemingly condemns these practitioners who perform under severe threats for their very participation in the war.

Finally in this category, one sub-stream of interest in interpreting has been an often theoretical, rather than professional, interest in the phenomenon of the 'natural interpreter'; that is, a bilingual who may demonstrate that bilingualism by translating at any time in an informal setting, not for professional purposes but in any social, familial or personal context. Arising from a long and well-established field of research and theory on bilingualism, this would be of tangential relevance to the area of the professional conduct of interpreting, except that so many instances in the natural translation research draw on examples of children or other bilinguals interpreting in situations where professional interpreters may well be used but are not. Recent work redrawing attention to the long-time theoretical work of Brian Harris (Mayor and Ivars 2011, Ivars and Mayor 2012) interestingly contains material that begins to argue for the benefits to bilingual children of having them performing interpreting tasks, rather than earlier views of the detrimental side of such practice. For our concern with ethics, however, wherever natural interpreters are permitted to interpret in any critical or institutional situation, ethical responsibility continues to rest with those granting such permission.

\section{Table 3: Interpreting as professional status}

\begin{tabular}{|l|l|l|l|}
\hline (Lack of) & Professional areas & \multicolumn{2}{|c|}{ Unprofessional } \\
\cline { 3 - 4 } Professional status & seen as conference & Mode of recruiting & Status per se \\
\cline { 3 - 4 } & interpreting, but & Locally recruited & Ad hoc \\
& now some other & Volunteer & Unprofessional \\
areas of liaison & & Natural \\
\hline
\end{tabular}




\section{Descriptions that avoid the use of the concept 'interpreter'}

Finally, we have descriptions where the terms interpreter is specifically avoided - linguistic mediator, cultural mediator or (in conflict situations) fixer.

Such avoidance would seem to be for one of two reasons - first, this may be in situations where the practitioner is in fact an interpreter but the ruling language policy or institutional practice is to reserve the term 'interpreter' to conference interpreting alone - as in the case of Italy, where such the description linguistic mediator is legislated (Pöchhacker 2008, Baraldi 2012). The term intercultural mediator favoured for many years in Flanders again stressed the mediation and cultural role of the practitioner, generally aimed towards enabling integration of immigrant populations, or paying particular attention to minority health care issues, where a substantial part of their role was indeed interpreting, but where interpreter was again not a favoured term for this kind of work (Bot \& Verrept 2013).

Such descriptions, where interpreting is the major (or sole) work undertaken, are different to other job descriptions that may involve language but where the person may or may not engage in interpreting - bilingual health worker for example, or multicultural teacher aide or versions thereof. In these cases, though the language spoken by the practitioner is of great significance, they may do their work largely monolingually (eg with patients or parents from a particular minority language group) but speak the majority language when reporting back. They may do no interpreting, or do a lot, depending on local guidelines, institutional policies or even individual initiative, though it is not always clear whether such role distinctions are understood, either by the practitioner or by those employing them.

This is also different to other descriptions such as in health interpreting where in some places the role of an interpreter may include such functions as cultural clarifier or patient advocate, but where the role is defined as that of interpreter, or different to the case of Interprétariat where the task clearly is interpreting.

The ethical implications of working under such descriptions is rarely documented; to the extent that they work as interpreters, and are paid for professional work as such, they may in many instances follow exactly the same ethics as an interpreter; indeed a description as a cultural mediator for example may be a hoped-for bringing about accord between culturally different interlocutors, but it would be an empirical questions as to what extent they do engage in this.

Pöchhacker's (2008) careful analysis of the notion of mediation usefully distinguishes between a generic linguistic sense of mediation as transferring meaning between two interlocutors with different languages on the one hand, and trying to bring about an accord between interlocutor or exercising independent agency on the other. However, when looking at the way terms such as linguistic mediation or intercultural mediation are used he finds such uncertainty as to what role is being understood that there is an "impossible conceptual confusion" (Pöchhacker 2008: 21). And Baraldi (2012) may have done as much to confuse as clarify concepts here with the notion of "dialogic mediation", with little certainty of any role boundaries, but perhaps in this way illustrating the wider institutional reality of indeterminacy of role when such descriptions are used.

The second reason for not using the terms interpreter arises at a more informal level, as documented in conflict situations such as Iraq or Afghanistan. Even though these personnel have an official title of 'interpreter' (either unmarked or as civilian or locally recruited interpreter) the informal fixer label arose in military jargon and refers to what they may do a 
lot of in conflict situations - not only interpreting but finding the people to interpret for who could be of interest to the military, briefing military personnel about that person or situation, warning of dangers, or even sourcing information independently. They may do largely interpreting or do hardly any interpreting at all (Inghilleri 2011). The ethical implications related to such personnel and descriptions of them has been covered above.

\section{Who does the defining?}

Finally, a critical issue in considering the above descriptions of interpreting is who does the describing and defining? Crucially, not all the descriptions arise from the profession itself; institutional definitions have often been important in naming a field and in some cases descriptions have come as epithets or categorisations by others. An approximate schema showing the defining process is shown here, noting that overlaps can occur between different sources of descriptions, and description will importantly not match self-ascription, for example in relation to the category of non-professional interpreting. In developing such a schema, it is acknowledged that the actual genesis of many of these terms has not always been adequately documented and would benefit from detailed historical research.

Table 4: Who defines what kind of interpreting

\begin{tabular}{|c|c|c|}
\hline $\begin{array}{l}\text { Defined by the profession } \\
\text { or professional literature } \\
\text { (self-ascription varies; the } \\
\text { most common is } \\
\text { interpreting) }\end{array}$ & $\begin{array}{l}\text { Defined by institutions } \\
\text { (with interpreters in these } \\
\text { categories usually using } \\
\text { the institutionally-defined } \\
\text { description) }\end{array}$ & $\begin{array}{l}\text { Defined by others (with } \\
\text { often interpreters in these } \\
\text { categories not using the } \\
\text { categories as self- } \\
\text { ascription) }\end{array}$ \\
\hline \multicolumn{3}{|l|}{$\begin{array}{l}\text { Interpreting } \\
\text { Conference interpreting } \\
\text { Community interpreting } \\
\text { Liaison interpreting } \\
\text { Monologic/dialogic } \\
\text { Business interpreting }\end{array}$} \\
\hline \multicolumn{3}{|c|}{$\begin{array}{l}\text { Public Service Interpreting } \\
\text { Court interpreting } \\
\text { Health interpreting }\end{array}$} \\
\hline & $\begin{array}{l}\text { Social interpreting } \\
\text { Interprétariat } \\
\text { 'Locally recruited' } \\
\text { 'Civilian' } \\
\text { (inter)cultural mediation } \\
\text { linguistic mediation }\end{array}$ & \\
\hline & & $\begin{array}{l}\text { Ad hoc interpreting } \\
\text { Unprofessional } \\
\text { interpreting } \\
\text { Volunteer interpreting } \\
\text { Natural interpreting } \\
\text { 'Fixer' }\end{array}$ \\
\hline
\end{tabular}


As we move from left to right on this spectrum we see moves

- from descriptions that arise largely from the profession (or authors writing as part of the profession) through more institutional definitions (usually shared by the practitioners and employers/vendors/users), to descriptions of interpreting that those performing those tasks would generally not use of themselves

- from an ethics of a liberal profession, to an ethics responding to, but tightly bound by, its institutional context; to a situation where issue of ethics only apply to those employing such personnel to perform interpreting, not the practitioners themselves.

- from considerations of codes of ethics devised by the profession itself to codes (or lack of codes) that arise from institutional considerations to complete absence of any knowledge of codes from its practitioners.

- from generic descriptions through institutional and site-specific or mode-specific descriptions to status-specific descriptions. It should be remembered of course that whatever the setting, most interpreters will refer to themselves generically as interpreters, without any adjective.

However, we do not see a move across the board from professional to non-professional work, except for the very last column of practitioners where such considerations may apply. A practitioner working in the Interprétariat, or as a conference or court or community interpreter, or indeed as a cultural mediator, so defined, may be doing equally professional work if this is defined as observing ethical standards, being remunerated and being recognised as a professional by others. Empirical considerations, rather than any overall descriptive a priori judgments, will determine if this is so in any specific instance.

Some very important but specific technical descriptions of interpreting can be mentioned as standing outside this schema: 'Telephone Interpreting' (or 'remote' or 'multimedia interpreting') and 'Sign Language Interpreting'. Such descriptions are largely uncontroversial and not contested; they are related to specific techniques and specific relations with interlocutors, but they largely share any ethical concerns with the general liaison interpreting profession operating in any settings. They may be considered as sub-modes of liaison interpreting or dialogic interpreting, and should not be categorised as institution-specific areas such as court interpreting or health interpreting.

\section{History and the now: adjectival interpreting or interpreting?}

The key to understanding the varying descriptions of interpreting, particularly liaison interpreting, as outlined above, is to understand the historical reasons for the prolific nature of these descriptions. While conference interpreting established itself quickly as practice and profession immediately post-war, the growth of liaison interpreting came more slowly and unevenly in widely varying contexts, and revealed widely varying responses to immigrants, the indigenous or the Deaf; to languages of others, or to forms of communication that were new or even threatening or unwelcome. And it revealed widely varying attitudes to practitioners of this diversity of interpreting. Thus, very different descriptions of interpreting and interpreters arose, matching very different provisions for their employ.

A crucial distinction here, drawn by Gentile in his 1997 paper, was between the activity of interpreting, and the status of an interpreter. In a field where one profession, that of conference interpreting, had been able to define itself and jealously guarded its professional integrity, having others claiming to be interpreters in very different settings and often very different professional socialisation - or none at all - produced responses ranging from sidelining to contempt, but always defining as other. As the professionalism of many 
fields of interpreting has increased, and as conference interpreters find themselves more engaging with liaison interpreting as a field and a practice, earier disengagement is giving way to more common understanding, as shown in the increasing attention paid to liaison interpreting by such bodies as AIIC and in conference interpreting training programs, as well as the increasing number of publications on liaison interpreting issues by conference interpreters past or current (Hertog and Reunbrouc1999). And conference interpreting is itself undergoing greater diversification with the arrival of many 'ñew' languages, more work outside the conference booth, greater interaction with a diversity of other interpreters, and a hitherto unseen evolving professional activism (Boéri 2008).

In ending on this historical note, it may be useful to ponder if this drive to provide adjectives for interpreting will also continue into the future. It is understandable that some of the specific specialisations of interpreting (court, health, conference interpreting) will continue to identify themselves with these fields and be so identified by others; indeed, it may even led to a strengthening of these field-specific descriptions precisely to stress their specialisation, especially if rates of professionalisation can increase and these areas distinguish themselves horizontally, no longer vertically or hierarchically, just as engineering can accommodate many specialisations (civil, chemical, electronic,...) without vertical hierarchy.

The chance of such horizontal professional recognition across all sites of liaison interpreting may be considered more problematic, despite the fact that many practitioners will always work across many fields and see themselves, generically, as interpreters (unmarked). Liaison interpreting in its many manifestations (including legal and health interpreting) is still faced with the overriding twin problems of often being dependent upon (arguably increasingly unreliable) public funding; and needing to accommodate a wider and wider range of languages with highly varying degrees of professional socialisation among its practitioners (Ozolins 2010). Given this environment, interpreters are not always masters of their own fate, and it is important to see the influence of institutions and enterprises in defining their sphere of action. This is not to abscond from ethical responsibility on the part of interpreters, but to understand what are the limits of responsibility that can realistically be ascribed to interpreters, given the descriptions and conditions under which they work.

It thus remains an open question as to whether the use of some adjectives and descriptions will fade, or even if those areas refusing to use the term interpreting at all in time will change their view and recognise the common purpose, albeit different sites, of interpreting. It may be some time before we can do so without resorting to endless adjectives. 


\section{References}

Angellelli, C.V. 2004a. Medical interpreting and cross-cultural communication. Cambridge: Cambridge University Press.

Angelelli C.V. 2004b. Revisiting the Interpreter's Role. Amsterdam/Philadelphia: Benjamins.

AUSIT [Australian Institute of Interpreters and Translators] (2012) Code of Ethics. [Available at www.ausit.org]

Baraldi, C. 2012 Interpreting as dialogic mediation. The relevance of expansions. In Baraldi and Gavioli: 297-326.

C. Baraldi and L. Gavioli (eds.), Coordinating Participation in Dialogue Interpreting. Amsterdam/Philadelphia: Benjamins.

Barsky, R.F. 1996. The interpreter as intercultural agent in Convention refugee hearings. The Translator 2(1): 45-63.

Boéri, J. 2008. A narrative account of the Babels vs. Naumann controversy. Competing perspectives on activism in conference interpreting. The Translator 14(1): 21-50.

Boéri, J. 2012. Ad hoc interpreting at the crossways between natural, professional, novice and expert interpreting. In Ivars and Mayor.

Bot. H. and H. Verrept. 2013. Role issues in the Low Countries: Interpreting in mental healthcare in the Netherlands and Belgium. In C.Schäffner, K.Kredens and Y.Fowler (eds.), Interpreting in a Changing Landscape. Selected paper from Critical Link 6. 117-131. Amsterdam/Philadelphia Benjamins.

Camayd-Freixa, E. 2013. Court interpreter ethics and the role of professional organizations. In C.Schäffner, K.Kredens and Y.Fowler (eds.), Interpreting in a Changing Landscape. Selected paper from Critical Link 6. 15-30. Amsterdam/Philadelphia: Benjamins.

Carr, S.E. et al. 1997 The Critical Link: Interpreters in the Community. Amsterdam/Philadelphia: Benjamins

CHIA [California Health Interpreters Association] 2002. California Standards for Healthcare Interpreters. [Available at www.chia.ws/standards.htm ]

Corsellis, A. 2008. Public Service Interpreting: First Steps. New York: Palgrave Macmillan.

de Pedro Ricoy, R. 2010. Training Public Service Interpreters in the UK: A fine balancing act. Journal of Specialised Translation 14: 100-120.

Dodds, J.M. 2011. Business culture versus interpreting culture. In M.J. Medina and S. Winteringham (eds.), Interpretazione e mediazione. 1-32. Rome: ARACNE.

Dean. R.K. and R.Q. Pollard. 2011. Context-based ethical reasoning in interpreting: A 
demand control schema perspective. The Interpreter and Translator Trainer 5(1): 155-182.

Erasmus, M. et al. eds. 1999. Liaison Interpreting in the Community. Pretoria: Van Schaik.

Erasmus, M. 1999b. Theoretical aspects of liaison interpreting: a South-African perspective. In Erasmus: 47-58.

Fenton, S. 2004. Expressing a well-founded fear: Interpreting in Convention refugee hearings. In: G. Hansen, K. Malmkjaer and D. Gile (eds.), Claims, Changes and Challenges in Translation Studies. 263-269. Amsterdam/Philadelphia: Benjamins.

Gentile, A. 1997 Community interpreting or not? Practices, standards and accreditation. In: Carr et al.: 109-118.

Gentile, A., U. Ozolins, and M. Vasilakakos. 1996. Liaison Interpreting: A Handbook. Carlton South, Vic., Australia: Melbourne University Press.

Hale, S. 2007. Community Interpreting. Basingstoke: Palgrave Macmillan.

Inghilleri, M. 2011. Interpreting Justice, Ethics, Politics and Language. London: Routledge.

Hertog E. and D. Reunbrouck. 1999. Building bridges between conference interpreters and liaison interpreters. In Erasmus, 263-277.

Ivars, M.A.J. and M.J.B. Mayor, eds. 2012. Interpreting Brian Harris: Recent Developments in Translatology. Bern: Peter Lang.

Kelly, N. 2008. Telephone Interpreting. [Bloomington:]Trafford.

Ko L. 1996. Business settings. In A. Gentile et al.: ch.9.

Ko. L. 2006. Fine-tuning the Code of Ethics for interpreters and translators. Translation Watch Quarterly 2(3): 45-62.

Mayor, M.J.B and M.A.J. Ivars, eds. 2011. Interpreting Naturally: A Tribute to Brian Harris. Bern: Peter Lang, 2011.

Mesa, A-M. 2000. The cultural interpreter: An appreciated professional. In R.P.Roberts et al. (eds.), The Critical Link 2: Interpreters in the Community. 67-79. Amsterdam/Philadelphia: Benjamins.

Metzger, M. 1999. Sign Language Interpreting: Deconstructing the Myth of Neutrality. Washington D.C.: Gallaudet University Press.

Meyer, B. 2002. Medical interpreting - some salient features. In G. Garzone and M. Viezzi (eds) Interpreting in the $21^{\text {st }}$ Century. 159-169. Amsterdam/Philadelphia: Benjamins.

Meyer, B. 2012. Ad hoc interpreting for partially language-proficient patients: Participation in multilingual constellations. In Baraldi and Gavioli: 99-114. 
Mikkelson, H. 2000. Interpreter ethics: A review of the traditional and electronic literature. Interpreting 5(1): 49-56.

NAJIT [National Association of Judiciary Interpreters and Translators] Code of Ethics and Professional Responsibilities. [Available at www.najit.org/about/NAJITCodeofEthicsFINAL.pdf ]

Niska, H. 1991. A new breed of interpreter for immigrants. Community interpreting in Sweden. In: C. Picken (ed.), ITI Conference 4. London: Aslib, 94-104.

NCIHC [National Council for Interpreting in Health Care]. 2004. Code of Ethics for Interpreters in Health Care. [Available at www.ncihc.org ].

NSGGCIS [National Standard Guide for Community Interpreting Services]. 2007. [Available at http://healthcareinterpretationnetwork.ca/?page $\mathrm{id}=92$ ].

Norström, E., K. Gustafsson and I. Fioretos. 2011. Behind Closed Doors - The significance of community interpreting for guaranteeing legal rights and integration; with a special focus on the reception of separated children and the processing of their asylum cases. [Available at www.tolkprojektet.se/eng_index.html ].

NRPSI [National Register of Public Service Interpreters]. 2011. Code of Professional Conduct. [Available at www.nrpsi.co.uk/pdf/CodeofConduct07.pdf ]

Ozolins, U. 2000. Communication needs and interpreting in multilingual settings: The international spectrum of response. In R.P. Roberts et al. (eds.), The Critical Link 2: Interpreters in the Community. 21-33. Amsterdam/Philadelphia: Benjamins.

Ozolins, U. 2010. Factors that determine the provision of Public Service Interpreting: Comparative perspectives on government motivation and language service implementation. Journal of Specialised Translation 14: 194-215.

Penn, C. and J. Watermeyer, 2012. Cultural brokerage and overcoming communication barriers: A case study from aphasia. In Baraldi and Gavioli: 269-296.

Pöchhacker, F. 1997. Is There Anybody Out There? Community Interpreting in Austria. In Carr et al.: 215-225

Pöchhacker, F. 2008. Interpreting as mediation. In C. Valero-Garcés and A. Martin (eds.), Crossing Borders in Community Interpreting. Definitions and Dilemmas. 9-26. Amsterdam/Philadelphia: Benjamins.

Pöchhacker, F. 2012. Interpreting participation: Conceptual analysis and illustration of the interpreter's role in interaction. In: Baraldi, and Gavioli: 45-70.

Pöchhacker, F. and W.Kolb. 2009. Interpreting for the record: A case study of asylum review hearings. In: S. Hale, U. Ozolins and L. Stern (eds.), The Critical Link 5. Quality in interpreting - a shared responsibility. 119-134. Amsterdam/Philadelphia: Benjamins. 
Pöllabauer, S. (2004) Interpreting in asylum hearings: Issues of role, responsibility and power. Interpreting 6(2): 143-180.

Roberts R.P. 1997. Community interpreting today and tomorrow. In Carr et al.: 7-26.

Sauvêtre, M. 2000. De l'intérpretariat au dialogue à trois. Pratiques européennes de l'intérpretariat en milieu social. In R.P.Roberts et al (eds.), The Critical Link 2: Interpreters in the Community. 35-45. Amsterdam/Philadelphia: Benjamins.

Shackman, J. 1984. The Right to be Understood: A handbook on working with, employing and training community interpreters. Cambridge: National Extension College.

Schweda-Nicholson, N. 1994. Professional ethics for court and community interpreters. In D.L. Hammond (ed.), Professional Issues for Translators and Interpreters. 79-98. Amsterdam/Philadelphia: Benjamins.

Takimoto, M. 2006. Interpreters' role perceptions in business dialogue interpreting situations. Monash University Linguistics Papers 5(1): 47-57.

Tebble H. 2012. Interpreting or interfering? In: Baraldi and Gavioli: 23-44.

Valero-Garcés, C. 2003. Responding to communication needs. Current issues and challenges in community interpreting and translating in Spain, In L. Brunette et al. (eds.), The Critical Link 3: Interpreting in the Community. 177-192. Amsterdam/Philadelphia: Benjamins.

Vermeiren, H, J. van Gucht, and L. De Bontridder. 2009. Standards as critical success factors in assessment: Certifying social interpreters in Flanders, Belgium. In C. Angelelli and H.E. Jacobson (eds.), Testing and Assessment in Translation and Interpreting Studies. A Call for Dialogue between Research and Practice. 297-329.

Amsterdam/Philadelphia: Benjamins. 